\title{
STATISTICAL ANALYSIS OF EXPERIMENTAL PARAMETERS IN SELECTIVE LASER SINTERING EXPERIMENT
}

\author{
J.-P. Kruth and S. Kumar* \\ Dept. of Mechanical Engineering Katholieke Universiteit Leuven, Belgium
}

\begin{abstract}
The paper presents the statistical analysis done to find the optimized values of selected parameters i.e. Scan Speed, Layer Thickness and Scan Spacing in the Selective Laser Sintering experiment and to search for the most significant parameter among parameters taken for experimentation. Signal-to-Noise (S/N) ratio has been determined from measured responses (Density, Hardness and Surface Roughness) of all nine experiments accomplished according to $L_{9}\left(3^{4}\right)$ Taguchi Design of Experiment using an iron-based powders as the building material and a modified DTM 2000 Sinterstation as the laser sintering machine. S/N ratio has been further used for doing Pareto ANOVA Analysis in order to find the most significant parameter. It has been observed that Scan Speed comes out to be the most significant one. The finding has been supported by making traditional ANOVA for all responses.
\end{abstract}

Key words: : Selective Laser Sintering, Design of Experiment, S/N Ratio, ANOVA, Iron Powders

\section{INTRODUCTION}

Selective Laser Sintering (SLS) is a rapidly growing technique for Rapid Prototyping and Rapid Manufacturing in which powders are selectively consolidated by a laser beam to produce 3D parts. The important parameters which

* corresponding author. Address: Department of Mechanical Engineering, Division PMA, Celestijnenlaan 300B, B-3001 Heverlee (Belgium), Tel: +32 1632 2772, Fax: +321632 2987

Email address: sanjay.kumar@mech.kuleuven.ac.be (S. Kumar). 
affect the SLS process are Scan Speed, Layer Thickness, Scan Spacing, Laser Power, Powder Size, Powder Size Distribution, Scanning Strategy, Base Platform Temperature and Atmosphere [1].

A Design of Experiment is a methodology of experimentation by which total information from a system can be obtained by doing minimum number of experiments. In a conventional approach of experimentation, at a time, one factor is kept varying, and all other factors are kept constant. The optimum conditions obtained in such conventional approach may not be a true optimum if interaction between the factors is present. To study factors and their interactions, factorial experiments and response surface designs are used. In the case of a full factorial design, the number of experiments is numerous, and it is practically not possible to carry out experiments in most of the cases, so fractional factorial experiments are investigated, which can substantially decrease the number of experiments while allowing to study the effects of various parameters and their interactions [2]. Though the technique is well known and has been widely used in the manufacturing processes, few works have been reported in the case of SLS [3]. The present work is an attempt to demonstrate the utility and applicability of this statistical technique in SLS experiments.

\section{EXPERIMENTAL EQUIPMENT AND POWDERS}

A sintering machine type DTM Sinterstation 2000 was used for conducting experiments. It is a commercial machine designed for sintering polymer powders, such as nylon as well as polymer coated metal powders. The key components of the machine are a laser, laser optics and scanning mirrors, part build cylinder, feed cartridges, and a roller recoating mechanism. To build a part, powder from one of the feed cartridges is spread in a thin uniform layer over the part bed surface. The sinterstation is originally equipped with $50 \mathrm{~W} \mathrm{CO}_{2}$ laser and a galvano mirror scanner capable of reaching a scan speed of $1500 \mathrm{~mm} / \mathrm{s}$. The machine has been upgraded with a $100 \mathrm{~W} \mathrm{CO}_{2}$ laser.

Powder is the basis for the process and properties of the powder determine the final properties of the built product. The powder mixture used here consists of spherical powders of $\mathrm{Cu}, \mathrm{Ni}$ and $\mathrm{Fe}_{3} \mathrm{P}$ and irregular $\mathrm{Fe}$ powders. The composition of the mixture is given in table 1 .

The selection of the component of the powder is based on the phase diagram of Fe-P and $\mathrm{Cu}-\mathrm{P}$ as an eutectic is formed at $10.2 \%$ and $8.3 \%$ respectively,which is helpful in lowering melting points of the powder mixture. This is the reason why the components $\mathrm{Fe}_{3} \mathrm{P}$ or $\mathrm{Cu}_{3} \mathrm{P}$ are favourable in making the process more energy efficient as pure Fe has a melting point of $1538^{\circ} \mathrm{C}$ and after alloying 
with a small amount of $\mathrm{P}$ this can be lowered to $1048^{\circ} \mathrm{C}$ [4].

\section{EXPERIMENTAL PARAMETERS AND PLAN}

Experiments are designed using an orthogonal array denoted by $L_{9}\left(3^{4}\right)$. In the notation $L_{9}\left(3^{4}\right), L$ indicates that the information is based on the Latin square arrangement of factors. A Latin square arrangement is a square matrix arrangement of factors with separable factor effects. The number 9 of the notation states the number of experiments required when using the orthogonal array while the number 4 of the notation is the maximum number of factors that can be studied using the array. The number 3 of the notation indicates the number of factor levels. In the present case only three experimental parameters i.e Scan Speed, Scan Spacing and Layer Thickness are investigated (i.e. varied). These are crucial parameters and their behaviour is briefly described below.

Scan speed is the speed by which laser beam scans over the powder bed during laser sintering. The higher the value of scan speed, the less time the laser beam will get to interact with the powder bed and it will give less transfer of heat energy necessary for melting and subsequently sintering of the powders. At the other extreme, lower value of scan speed can give rise to vapourisation of the powders and will decrease the production speed of a product.

Scan Spacing is the distance between two consecutive laser scan tracks on the powder bed surface. Higher value of scan spacing will not allow all powder area between successive scan tracks to be sintered by the laser beam. Narrow value of scan spacing will make some powder area to be over exposed to the laser beam. Therefore, the scan spacing should be such to cover all the aimed powder area while not over exposing some powder. The value of scan spacing is strongly dependent on the spot size of the laser beam.

Layer thickness is another important parameter. It is the thickness of the successive layers of powder bed. Higher value of layer thickness does not allow enough laser energy to spread through the layer into the supporting underlayer such as to ensure good connection between successive layers. With a small layer thickness, there is apprehension that the powder layer will not be able to remain uniform during its deposition. Smaller layer thickness also increases the build time significantly and negates the 'rapidity' of Rapid Prototyping.

The levels for Scan Speed, Scan Spacing and Layer Thickness selected for experimentation are $60,80,100 \mathrm{~mm} / \mathrm{s} ; 0.10,0.15,0.20 \mathrm{~mm} ; 0.10,0.15,0.20$ $\mathrm{mm}$ respectively and are arranged in column no. 1, 3 and 4 respectively of the orthogonal array $L_{9}\left(3^{4}\right)$. Column 2 could not be used as there were only three input parameters though it was planned to be used for the parameter Laser 
Power which has been kept constant at a maximum of $60 \mathrm{~W}$ in the present plan[5].

\section{MECHANICAL CHARACTERIZATION AND RESULTS}

In order to identify the mechanical properties of laser sintered products, Hardness, Density and Surface Roughness measurements were carried out.

For finding out the hardness, Brinell hardness of samples was determined by impressing the sample with a steel ball of diameter $10 \mathrm{~mm}$ by a load of $500 \mathrm{~kg}$ for a time of $10 \mathrm{~s}$. The hardness was then determined by measuring the diameter of the impression. The density of the sample is an important property to quantify as it gives an estimation over the number of pores present in samples. The density was measured according to the Archimedes principle by weighing the samples in air and subsequently in ethanol after coating with lacquer. The coating was used to avoid the absorption of ethanol in specimens during measurement. While, the surface roughness was measured using a Form Talysurf 120L instrument from Rank Taylor Hobson and adjusting a cut-off length of $2.5 \mathrm{~mm}$.

The results of tests namely hardness, density and surface roughness are shown in table 2 .

The data given in the table are average values $\left(\bar{y}_{j}\right)$ of various measurements taken for each set of experiments. The variations $\left(S^{\prime}\right)$ in data for each experiments have been found to be about $10 \%, 6 \%$ and $1 \%$ respectively for hardness, surface roughness and density.

The variations $\left(S^{\prime}\right)$ have been calculated using following equations 1 and 2 which has been used to find variance for each set of experiments using equation 3:

$$
\begin{gathered}
S_{j}{ }^{\prime}=\sqrt{\frac{\sum_{i=1}^{n}\left(y_{i}-\overline{y_{j}}\right)^{2}}{n-1}} \\
S^{\prime}=\frac{1}{9} \sum_{j=1}^{9} \frac{S_{j}{ }^{\prime}}{y_{j}} \times 100 \\
S_{j}=\frac{\bar{y}_{j} \times S^{\prime}}{100}
\end{gathered}
$$

As the number of specimens made for all set of experiments were not the same and, for all responses the number of specimens required to get same number of observations were different, a uniform variation $\left(S^{\prime}\right)$ for a given 
response is calculated by using all observations made within one experiment set (1) and averaging over all experiment sets (2). This also became necessary as not enough specimens to get sufficient number of observations could be made for some set of experiment sets. It has also been observed for a given experiment set that the experimental error in observations coming out from many specimens are not more than that observed from a single specimen.

These variations $S_{j}$ are used further in equations 5 and 7 for determining the signal-to-noise $(\mathrm{S} / \mathrm{N})$ ratio as explained in the section below. However, it will be shown that their value has little influence on the result of the $\mathrm{S} / \mathrm{N}$ ratio analysis performed below.

\section{ANALYSIS USING SIGNAL-TO-NOISE RATIO}

The signal-to-noise ratio ( $\mathrm{S} / \mathrm{N}$ ratio) is used in evaluating the quality of the product and is an objective measure of quality that takes both the mean and variance into account. The signal-to-noise ratio measures the level of performance and the effect of noise factors on performance and is an evaluation of the stability of performance of an output characteristics [2]. For determining signal-to-noise ratio for the response Hardness and Density, higher-is-better type $\mathrm{S} / \mathrm{N}$ ratio has been selected which is given by equation 4 for $n$ observations and is rewritten as equation 5 in terms of variance around the average values.

$$
\begin{gathered}
\left(\frac{S}{N}\right)_{j}=-10 \log _{10}\left[\frac{1}{n} \sum_{i=1}^{n} \frac{1}{y_{i}^{2}}\right] \\
\left(\frac{S}{N}\right)_{j}=-10 \log _{10}\left[\frac{1}{\bar{y}_{j}^{2}}\left(1+\frac{3 S_{j}^{2}}{\bar{y}_{j}^{2}}\right)\right]
\end{gathered}
$$

In case of the response Surface Roughness, it is aimed to achieve a surface roughness as small as possible and therefore $\mathrm{S} / \mathrm{N}$ ratio of type lower-is-better has been selected, which has been given by equation 6 for $n$ observations and is rewritten as equation 7 in terms of variance around the average values.

$$
\begin{aligned}
& \left(\frac{S}{N}\right)_{j}=-10 \log _{10}\left[\frac{1}{n} \sum_{i=1}^{n} y_{i}^{2}\right] \\
& \left(\frac{S}{N}\right)_{j}=-10 \log _{10}\left[S_{j}^{2}+\left(\bar{y}_{j}\right)^{2}\right]
\end{aligned}
$$

where $S_{j}^{2}=$ variance around the average value of $y_{j}$ namely, $\bar{y}_{j}$ where $y_{j}$ is the response. 
The $\mathrm{S} / \mathrm{N}$ ratios calculated for all responses using above equations 5 and 7 , have been given in table 3 .

Table 3 has been used to calculate the mean $\mathrm{S} / \mathrm{N}$ ratio for each level of the factors from all responses and is given in table 4 .

Table 4 has been used to find the optimum values for factors. The levels which give the highest $\mathrm{S} / \mathrm{N}$ ratio for density and hardness are considered the best or the optimal ones and have been highlighted by bold numbers in table 4 . Similarly, the values corresponding to the smallest $\mathrm{S} / \mathrm{N}$ ratio for roughness is also highlighted. For the layer thickness, the best levels suggested by surface roughness do not agree with that of hardness and density. As mechanical properties more important the level implied by density and hardness is accepted as the best one. The best level is shown in table 7 together with the worst level (corresponding to smallest $\mathrm{S} / \mathrm{N}$ ratio for density and hardness).

Equations 5 and 7 are sometimes used while neglecting the variation (i.e. putting $\left.S_{j}=0\right)$. The $\mathrm{S} / \mathrm{N}$ ratio then basically comes down to re-scaling the obtained response (hardness, density, surface roughness respectively) according to a logarithmic scale. Using the logarithmic of the response has the advantage that the impact of extreme values will be lowered. Recalculating the $\mathrm{S} / \mathrm{N}$ ratio without variance results in tables 5 and 6 . They gave the same trend as have been obtained earlier as illustrated by tables 3 and 4 .

Table 5 has been used to calculate the $\mathrm{S} / \mathrm{N}$ ratio for each level of factors from all responses as given in table 6 . The absence of variance for determining $\mathrm{S} / \mathrm{N}$ ratio has given a difference in mean $\mathrm{S} / \mathrm{N}$ ratio of about 0.1 for hardness, 0.01 for surface roughness and no variation for response density. These figures could change with a change in measuring unit of the response, nevertheless, they show that mean output values alone can be taken for determining output parameters. It has also been evidenced by many publications [6-8].

From table 7, it is clear that the best value (optimal value within the tested range)for scan speed, scan spacing and layer thickness always coincides with one extreme of the tested parameter range. This would necessitate to increase the tested range so that the optimum value could be roughly in the middle of the range. The range needs to be extended towards the input settings giving rise to more applied laser energy to powders. This is possible either by decreasing scan spacing, layer thickness and scan speed or/and by increasing the laser power. However, rapid and economic requirements for productions restrain decreasing the scan speed, scan spacing and layer thickness to minimum values.

Figures 1, 2, 3 show the change in mean $\mathrm{S} / \mathrm{N}$ ratio against change in levels for the responses hardness, density and surface roughness respectively. These figures illustrate clearly the optimized parameter values which are tabulated in 
table 7. For convenience of illustration, the factors Scan Speed, Scan Spacing and Layer Thickness are respectively denoted by $\mathrm{A}, \mathrm{B}$ and $\mathrm{C}$. While their levels in the increasing order have been shown by $A_{1}, A_{2}, A_{3}, B_{1}, B_{2}, B_{3}$ and $C_{1}, C_{2}, C_{3}$ respectively.

\section{DATA ANALYSIS BY ANOVA TECHNIQUE}

Analysis of variance (ANOVA) is a method of partitioning variability into identifiable sources of variation. In this section, ANOVA has been made for all three responses namely, Hardness, Density and Surface Roughness and is given in tables $8,9,10$ respectively.

ANOVA has been made by determining the Sum of Squares $(S S)$ for various input factors namely A, B, C using equations 8, 9, 10 respectively. While the Sum of Squares for error i.e. $S S_{E}$ has been determined by subtracting the sum of Sum of Squares for all factors from the total Sum of Squares $\left(S S_{T}\right)$ according to the equations 12. $S S_{T}$ has been calculated by using equation 11 [9]. $S S_{E}$ can also be independently computed by using column 2 of orthogonal array $L_{9}\left(3^{4}\right)$. As column 2 of the array was not used for accommodating an input parameter, it can be used for the calculation of error.

$$
\begin{gathered}
S S_{A}=\frac{A_{1}^{2}}{3}+\frac{A_{2}^{2}}{3}+\frac{A_{3}^{2}}{3}-\frac{T^{2}}{9} \\
S S_{B}=\frac{B_{1}^{2}}{3}+\frac{B_{2}^{2}}{3}+\frac{B_{3}^{2}}{3}-\frac{T^{2}}{9} \\
S S_{C}=\frac{C_{1}^{2}}{3}+\frac{C_{2}^{2}}{3}+\frac{C_{3}^{2}}{3}-\frac{T^{2}}{9} \\
S S_{T}=\left[\sum_{j=1}^{9}\left(\bar{y}_{j}\right)^{2}\right]-\frac{T^{2}}{9} \\
S S_{E}=S S_{T}-S S_{A}-S S_{B}-S S_{C}
\end{gathered}
$$

Where $\mathrm{T}$ is given by

$$
T=\sum_{j=1}^{9} \bar{y}_{j}
$$


Mean sum of square is found by dividing the sum of squares by the degree of freedom. The F-ratio is calculated by dividing the Mean sum of squares of the respective parameters (A, B or $\mathrm{C}$ ) by the Mean sum of square corresponding to Error. This ratio is used for testing the significance of factors. When $\mathrm{F}$ is much greater than 1, the effect of control factor is large compared to the variance due to experimental error and interaction effects.

The F-ratio values in bold in tables 8, 9 and 10 show the significant factors. It has been found that table 8, 9, give respectively the factor Layer Thickness, Scan Speed, and table 10 gives the factor Scan Speed and Scan Spacing as significant factors. As all the factors chosen for the experiments are significant, it implies no factor is insignificant while the factor Scan Speed is more significant than others.

\section{PARETO ANOVA ANALYSIS}

One of the methods to analyze data for process optimization is the use of Pareto ANOVA. Pareto ANOVA is a simplified ANOVA method which uses Pareto principles. It does not require an ANOVA table and therefore does not use F-tests. S/N ratio is used to make a Pareto ANOVA.

Pareto ANOVA made for the response Hardness, Density and Surface Roughness has been given in table 11, 12 and 13 respectively. For making it, S/N ratios obtained for a type of level of a factor are taken from table 3 and are added. For a given factor, the square of the difference for each combination of levels is computed and their sum is taken. In this way, for each factor and also for the error, the sum of squares of difference (SD) is determined as shown in tables 11, 12 and 13. The percentage contribution for each factor is determined by dividing each SD corresponding to each factor by the summation of SD. The highest percentage value gives the highest significance of the factor.

The percentage contribution factor which shows the significant factor has been highlighted by making the number bold in the Pareto ANOVA table. The results are identical to that found from the conventional ANOVA analysis. Pareto diagrams have been made for illustrating the significance of the factors. The diagrams are shown in figures 4, 5 and 6 for the response hardness, density and surface roughness respectively. The error has been shown by $\mathrm{A}^{*} \mathrm{C}$ in the Pareto diagram. 


\section{CONCLUSIONS}

Planned experiments performed according to orthogonal arrays followed by analysis using Signal-to-Noise ratio is useful to identify the optimal parameters and can be used for optimization as function of the machine, powders or process in laser sintering experiment. Small variations observed in the measured valued is not detrimental in finding out the optimized parameters, which has been shown by computing $\mathrm{S} / \mathrm{N}$ ratio with and without taking into account variations in the responses. Making ANOVA for various responses gives an insight into the relative significance of the parameters and has confirmed the finding obtained using $\mathrm{S} / \mathrm{N}$ ratio. As all the factors chosen for the experiments are significant, the analysis implies no factor is insignificant while the factor Scan Speed is relatively more significant than others.

\section{Acknowledgements}

The fruitful suggestions given by Prof. Paul Darius, Department of Agrotechnique and Economics is thankfully acknowledged.

One of the authors (S. Kumar) would also like to express his gratitude to Ministry of Human Resources Development, India and Ministry of Flemish Community, Belgium for facilitating his stay in Belgium through Belgium Government Scholarships.

\section{References}

[1] S. Kumar. Selective laser sintering: a qualitative and objective approach. JOM, vol 55, No 10, pp. 43-47, 2003.

[2] W. Y. Fowlkes and C. M. Creveling. Engineering methods for robust product design. Addison-Wesley Publishing Company, Reading Massachusetts 01867, 1995.

[3] H.-J. Yang, P. J. Hwang, and S. H. Lee. A study on shrinkage compensation of the sls process by using the taguchi method. Scripta Materialia, Vol. 41, No. 11, pp. 12291234, 1999.

[4] J. P. Kruth, P. Mercelis, J. Van Vaerenbergh, L. Froyen, and M. Rombouts. Advances in selective laser sintering. In 1st International Conference on Advance Research in Virtual and Rapid Prototyping, Leiria, Spain, Oct 1-4, pp. 59-70, 2003. 
[5] J. P. Kruth, L. Froyen, S. Kumar, M. Rombouts, and J. Van Vaerenbergh. Study of laser-sinterability of iron-based powder mixture. 10th French Rapid Prototyping Conference, Paris, France, September 14-15, 2004.

[6] A. Alsaran, A. Celik, and C. Celik. Determination of the optimum conditions for ion nitriding of aisi 5140 steel. Surface and Coatings Technology, Vol. 160, pp. 219-226, 2002.

[7] J. A. Ghani, I. A. Choudhury, and H. H. Hasan. Application of taguchi method in the optimization of end milling parameters. Journal of Materials Processing Technology, vol 145, pp. 84-92, 2004.

[8] C. B. Srinivasan, N. L. Narsimhan, and S. V. Ilango. Development of rapid-set high-strength cement using statistical experimental design. Cement and Concrete Research, 33, pp. 1287-1292, 2003.

[9] P. J. Ross. Taguchi techniques for quality engineering. McGraw-Hill Book Company, United States, 1988. 


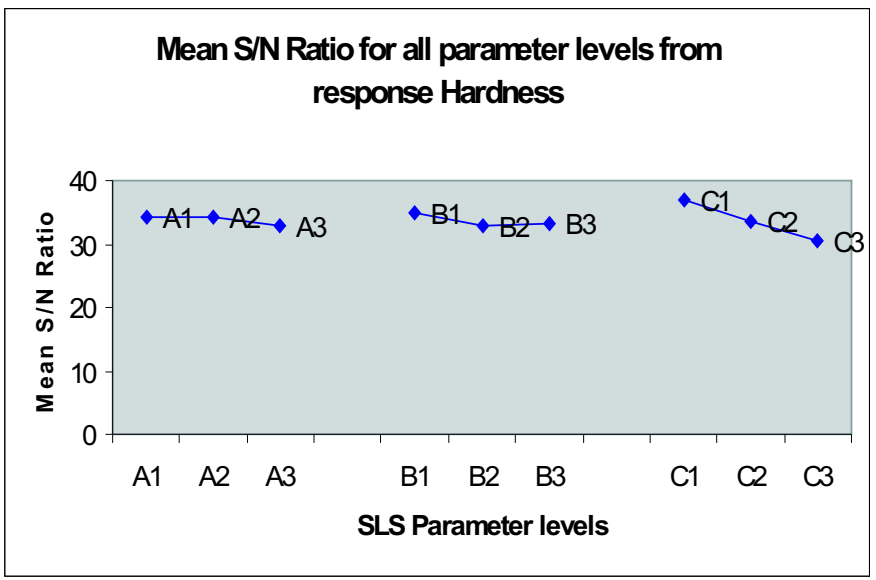

Fig. 1. Mean S/N Ratio for all parameter levels from response Hardness

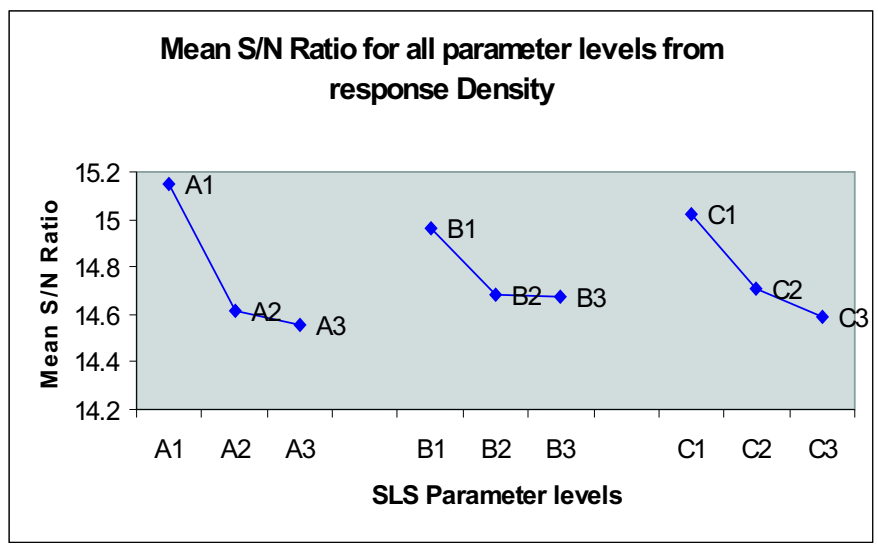

Fig. 2. Mean S/N Ratio for all parameter levels from response Density

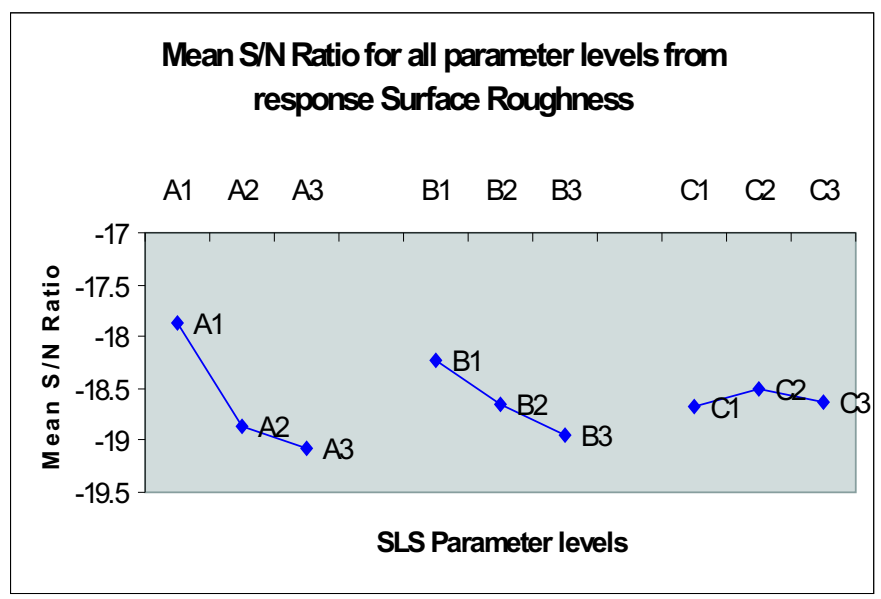

Fig. 3. Mean S/N Ratio for all parameter levels from response Surface Roughness 


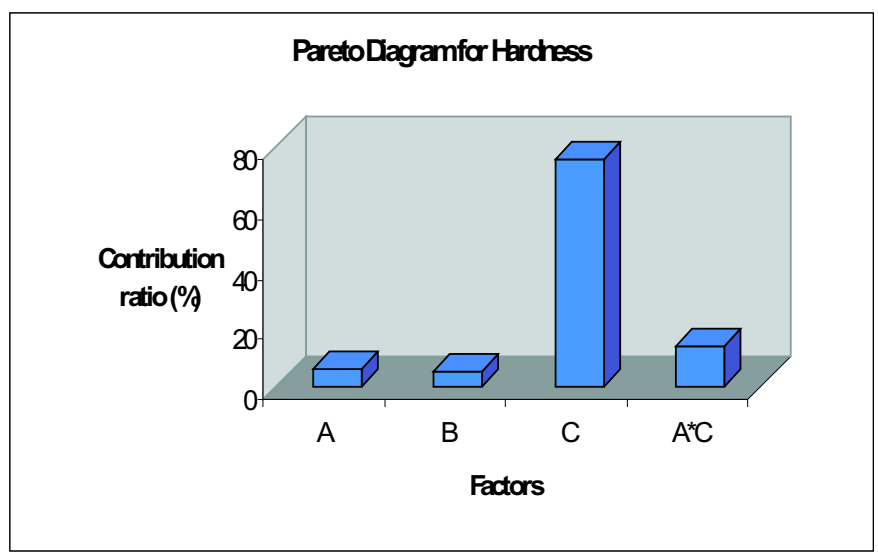

Fig. 4. Pareto Diagram for Hardness

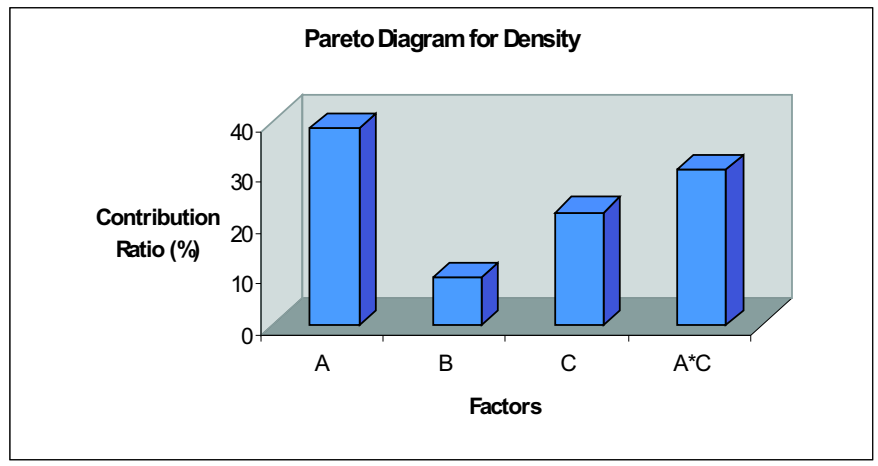

Fig. 5. Pareto Diagram for Density

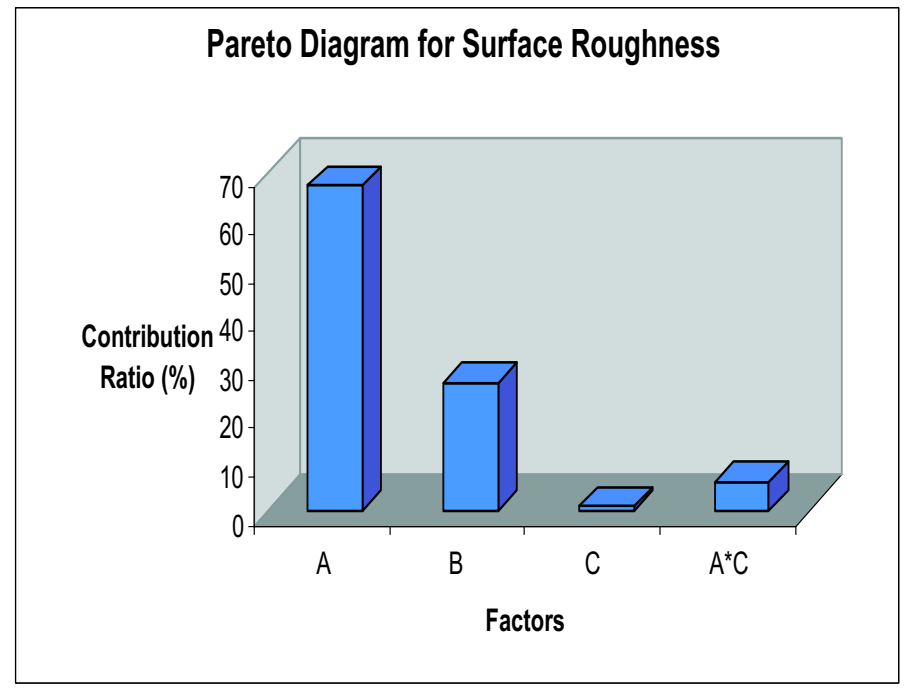

Fig. 6. Pareto Diagram for Surface Roughness 


\begin{tabular}{|ccccc|}
\hline Element & $\mathrm{Fe}$ & $\mathrm{Ni}$ & $\mathrm{Cu}$ & $\mathrm{Fe}_{3} \mathrm{P}$ \\
\hline Weight Percentage & 50 & 20 & 15 & 15 \\
\hline Size $(\mu \mathrm{m})$ & $<50$ & 5 & $<50$ & $<50$ \\
\hline
\end{tabular}

Table 1

Composition of the powder mixture

\begin{tabular}{|cccc}
\hline Experiment sets & $\begin{array}{c}\text { Brinell Hardness } \\
\left(\mathrm{kg} / \mathrm{mm}^{3}\right)\end{array}$ & $\begin{array}{c}\text { Density } \\
\left(\mathrm{g} / \mathrm{cm}^{3}\right)\end{array}$ & $\begin{array}{c}\text { Surface Roughness } \\
\left(R_{a}\right)\left(\mu_{m}\right)\end{array}$ \\
\hline 1 & 92.58 & 5.91 & 7.36 \\
\hline 2 & 53.43 & 5.85 & 7.83 \\
\hline 3 & 29.77 & 5.42 & 8.28 \\
\hline 4 & 33.59 & 5.12 & 8.60 \\
\hline 5 & 82.63 & 5.69 & 9.26 \\
\hline 6 & 50.35 & 5.34 & 8.44 \\
\hline 7 & 42.46 & 5.15 & 9.01 \\
\hline 8 & 40.86 & 5.56 & 8.70 \\
\hline 9 & 50.35 & 5.33 & 9.25 \\
\hline
\end{tabular}

Table 2

Values of Hardness, Density and Surface Roughness for $L_{9}$ Experiments 


\begin{tabular}{|cccc|}
\hline \multirow{2}{*}{ Experiment No } & \multicolumn{3}{c|}{ S/N ratio from } \\
\cline { 2 - 4 } & Hardness & Density & Surface Roughness \\
\hline 1 & 39.20 & 15.43 & -17.35 \\
\hline 2 & 34.43 & 15.34 & -17.90 \\
\hline 3 & 29.35 & 14.68 & -18.37 \\
\hline 4 & 30.40 & 14.18 & -18.70 \\
\hline 5 & 38.21 & 15.10 & -19.35 \\
\hline 6 & 33.91 & 14.55 & -18.54 \\
\hline 7 & 32.43 & 14.23 & -19.11 \\
\hline 8 & 32.10 & 14.90 & -18.81 \\
\hline 9 & 33.91 & 14.53 & -19.34 \\
\hline
\end{tabular}

Table 3

$\mathrm{S} / \mathrm{N}$ ratio (Signal-to-Noise ratio) from various responses

\begin{tabular}{|ccccc|}
\hline \multicolumn{2}{|c|}{ Factors } & \multicolumn{3}{c|}{ Mean S/N ratio from } \\
\hline Name & Levels & Hardness & Density & Surface Roughness \\
\hline Scan Speed & 60 & $\mathbf{3 4 . 3 3}$ & $\mathbf{1 5 . 1 5}$ & $\mathbf{- 1 7 . 8 7}$ \\
\cline { 2 - 5 }$(\mathrm{mm} / \mathrm{s})$ & 80 & 34.17 & 14.61 & -19.08 \\
\cline { 2 - 5 } & 100 & 32.94 & 14.56 & -19.07 \\
\hline Scan Spacing & 0.10 & $\mathbf{3 5 . 0 7}$ & $\mathbf{1 4 . 9 6}$ & $\mathbf{- 1 8 . 2 3}$ \\
\cline { 2 - 5 }$(\mathrm{mm})$ & 0.15 & 32.91 & 14.69 & -18.64 \\
\cline { 2 - 5 } & 0.20 & 33.33 & 14.67 & -18.94 \\
\hline Layer & 0.10 & $\mathbf{3 7 . 1 1}$ & $\mathbf{1 5 . 0 2}$ & -18.68 \\
\cline { 2 - 5 } Thickness & 0.15 & 33.59 & 14.71 & $\mathbf{- 1 8 . 5 1}$ \\
\cline { 2 - 5 }$($ mm) & 0.20 & 30.61 & 14.59 & -18.63 \\
\hline
\end{tabular}

Table 4

Mean S/N ratio (Signal-to-Noise ratio)for various levels from various responses 


\begin{tabular}{|cccc|}
\hline \multirow{2}{*}{ Experiment No } & \multicolumn{3}{c|}{ S/N ratio from } \\
\cline { 2 - 4 } & Hardness & Density & Surface Roughness \\
\hline 1 & 39.33 & 15.43 & -17.34 \\
\hline 2 & 34.56 & 15.34 & -17.88 \\
\hline 3 & 29.48 & 14.68 & -18.36 \\
\hline 4 & 30.52 & 14.19 & -18.69 \\
\hline 5 & 38.34 & 15.10 & -19.33 \\
\hline 6 & 34.04 & 14.55 & -18.53 \\
\hline 7 & 32.56 & 14.24 & -19.09 \\
\hline 8 & 32.22 & 14.90 & -18.79 \\
\hline 9 & 34.04 & 14.53 & -19.32 \\
\hline
\end{tabular}

Table 5

$\mathrm{S} / \mathrm{N}$ ratio (Signal-to-Noise ratio) from various responses without considering variation

\begin{tabular}{|ccccc|}
\hline \multicolumn{2}{|c|}{ Factors } & \multicolumn{3}{c|}{ Mean S/N ratio from } \\
\hline Name & Levels & Hardness & Density & Surface Roughness \\
\hline Scan Speed & 60 & $\mathbf{3 4 . 4 6}$ & $\mathbf{1 5 . 1 5}$ & $\mathbf{- 1 7 . 8 6}$ \\
\cline { 2 - 5 }$(\mathrm{mm} / \mathrm{s})$ & 80 & 34.30 & 14.61 & -18.85 \\
\cline { 2 - 5 } & 100 & 32.94 & 14.56 & -19.07 \\
\hline Scan Spacing & 0.10 & $\mathbf{3 5 . 2 0}$ & $\mathbf{1 4 . 9 6}$ & $\mathbf{- 1 8 . 2 2}$ \\
\cline { 2 - 5 }$(\mathrm{mm})$ & 0.15 & 33.04 & 14.81 & -18.63 \\
\cline { 2 - 5 } & 0.20 & 33.46 & 14.67 & -18.93 \\
\hline Layer & 0.10 & $\mathbf{3 7 . 2 4}$ & $\mathbf{1 5 . 0 2}$ & -18.66 \\
\cline { 2 - 5 } Thickness & 0.15 & 33.72 & 14.71 & $\mathbf{- 1 8 . 5 5}$ \\
\cline { 2 - 5 }$(\mathrm{mm})$ & 0.20 & 30.74 & 14.59 & -18.61 \\
\hline
\end{tabular}

Table 6

Mean S/N ratio (Signal-to-Noise ratio)for various levels from various responses without considering variation 


\begin{tabular}{|ccc|}
\hline Factors & Best Level & Worst Level \\
\hline Scan Speed $(\mathrm{mm} / \mathrm{s})$ & 60 & 100 \\
\hline Scan Spacing $(\mathrm{mm})$ & 0.10 & 0.20 \\
\hline Layer Thickness $(\mathrm{mm})$ & 0.10 & 0.20 \\
\hline
\end{tabular}

Table 7

The Best and Worst levels for factors inferred from mean $\mathrm{S} / \mathrm{N}$ ratio

\begin{tabular}{|ccccc|}
\hline Source & Sum of Squares & Degree of Freedom & $\begin{array}{c}\text { Mean sum } \\
\text { of squares }\end{array}$ & F-ratio \\
& & & 163.36 & 0.8 \\
\hline A (Scan Speed) & $\left(S S_{A}\right) 326.72$ & 2 & 183.20 & 0.9 \\
\hline B (Scan Spacing) & $\left(S S_{B}\right) 366.41$ & 2 & 1265.6 & $\mathbf{6 . 1 9}$ \\
\hline C ( Layer Thickness) & $\left(S S_{C}\right) 2531.19$ & 2 & 204.58 & 1 \\
\hline Error & $\left(S S_{E}\right) 409.17$ & 2 & & \\
\hline Total & $\left(S S_{T}\right) 3633.49$ & 8 & & \\
\hline
\end{tabular}

Table 8

ANOVA for Hardness

\begin{tabular}{|ccccc|}
\hline Source & Sum of Squares & Degree of Freedom & $\begin{array}{c}\text { Mean sum } \\
\text { of squares }\end{array}$ & F-ratio \\
\hline A (Scan Speed) & $\left(S S_{A}\right) 0.26$ & 2 & 0.13 & $\mathbf{1 . 2 7}$ \\
\hline B (Scan Spacing) & $\left(S S_{B}\right) 0.06$ & 2 & 0.03 & 0.3 \\
\hline C (Layer Thickness) & $\left(S S_{C}\right) 0.12$ & 2 & 0.06 & 0.6 \\
\hline Error & $\left(S S_{E}\right) 0.21$ & 2 & 0.1 & 1 \\
\hline Total & $\left(S S_{T}\right) 0.66$ & 8 & & \\
\hline
\end{tabular}

Table 9

ANOVA for Density

\begin{tabular}{|ccccc|}
\hline Source & Sum of Squares & Degree of Freedom & $\begin{array}{c}\text { Mean sum } \\
\text { of squares }\end{array}$ & F-ratio \\
\hline A ( Scan Speed) & $\left(S S_{A}\right) 2.29$ & 2 & 1.15 & $\mathbf{1 2 . 1}$ \\
\hline B (Scan Spacing) & $\left(S S_{B}\right) 0.71$ & 2 & 0.35 & $\mathbf{3 . 7 3}$ \\
\hline C (Layer Thickness) & $\left(S S_{C}\right) 0.06$ & 2 & 0.03 & 0.3 \\
\hline Error & $\left(S S_{E}\right) 0.19$ & 2 & 0.1 & 1 \\
\hline Total & $\left(S S_{T}\right) 3.24$ & 8 & & \\
\hline
\end{tabular}

Table 10

ANOVA for Surface Roughness 


\begin{tabular}{|ccccc|}
\hline \multirow{2}{*}{ Levels } & \multicolumn{4}{c|}{ S/N ratio for Factors } \\
\cline { 2 - 5 } & Scan Speed & Scan Spacing & Layer Thickness & Error \\
\hline 1 & 102.98 & 105.21 & 111.33 & 102.03 \\
\hline 2 & 102.52 & 98.73 & 100.77 & 104.74 \\
\hline 3 & 98.44 & 99.99 & 91.84 & 97.17 \\
\hline SD & 37.23 & 28.81 & 459.49 & 80.89 \\
\hline \% contribution ratio & 6.14 & 4.75 & $\mathbf{7 5 . 7 7}$ & 13.34 \\
\hline
\end{tabular}

Table 11

Pareto ANOVA analysis for Hardness

\begin{tabular}{|ccccc|}
\hline \multirow{2}{*}{ Levels } & \multicolumn{4}{c|}{ S/N ratio for Factors } \\
\cline { 2 - 5 } & Scan Speed & Scan Spacing & Layer Thickness & Error \\
\hline 1 & 45.45 & 44.88 & 45.06 & 43.85 \\
\hline 2 & 43.83 & 44.06 & 44.13 & 45.34 \\
\hline 3 & 43.67 & 44.01 & 43.76 & 43.76 \\
\hline SD & 3.21 & 0.75 & 1.83 & 2.51 \\
\hline \% contribution ratio & $\mathbf{3 8 . 6 7}$ & 9.06 & 22.02 & 30.26 \\
\hline
\end{tabular}

Table 12

Pareto ANOVA analysis for Density

\begin{tabular}{|ccccc|}
\hline \multirow{2}{*}{ Levels } & \multicolumn{4}{c|}{ S/N ratio for Factors } \\
\cline { 2 - 5 } & Scan Speed & Scan Spacing & Layer Thickness & Error \\
\hline 1 & -53.62 & -54.70 & -56.04 & -55.17 \\
\hline 2 & -56.60 & -55.93 & -55.54 & -56.04 \\
\hline 3 & -57.25 & -56.83 & -55.89 & -56.26 \\
\hline SD & 13.64 & 5.36 & 0.14 & 1.23 \\
\hline \% contribution ratio & $\mathbf{6 6 . 9 7}$ & $\mathbf{2 6 . 3 0}$ & 0.70 & 6.04 \\
\hline
\end{tabular}

Table 13

Pareto ANOVA analysis for Surface Roughness 